\title{
Real-world data on the dose-related effect of arsenic trioxide in the relapse of acute promyelocytic leukemia
}

\author{
SHA GONG ${ }^{1}$, HUAIYU WANG ${ }^{1}$, HUIYUN ZHANG $^{2}$, WEI LIU $^{3}$, XINXIN ZHANG $^{1}$ and CHENYANG ZHAO $^{1}$ \\ ${ }^{1}$ Department of Hematology, First Affiliated Hospital of Xi'an Jiaotong University, Xi'an, Shaanxi 710061; \\ ${ }^{2}$ Department of Oncology, Qinghai Provincial People's Hospital, Xining, Qinghai 810000; \\ ${ }^{3}$ Department of Hematology, The First People's Hospital of Yulin, Yulin, Shaanxi 719000, P.R. China
}

Received November 20, 2019; Accepted August 24, 2020

DOI: $10.3892 / \mathrm{mco} .2020 .2161$

\begin{abstract}
Acute promyelocytic leukemia (APL) has become a highly curable disease with all-trans retinoic acid-based regimens. However, following the administration of arsenic trioxide (ATO), the relapse rate remains at $1-10 \%$. It is not known whether the dosage of ATO is associated with the relapse rate in real-world settings. According to 2019 National Comprehensive Cancer Network guidelines, the recommended cumulative ATO dosage in post-remission therapy is $7.95-12 \mathrm{mg} / \mathrm{kg}$ in APL. In the current study, 112 patients with newly diagnosed APL receiving a combination of all-trans retinoic acid, anthracycline-based chemotherapy and different dosages of ATO for variable courses, were divided into the high-dose (ATO dosage, $\geq 12 \mathrm{mg} / \mathrm{kg}$ ) and low-dose groups (ATO dosage, $<12 \mathrm{mg} / \mathrm{kg}$ ). Relapse risk factors were analyzed by multiple factor analysis. The relationship between relapse rate and ATO dosage in post-remission was elucidated by determining the 4-year cumulative incidence of relapse (CIR). Based on the ATO dosage in post-remission therapy, 72 (64.3\%) patients were in the low-dose group and 40 (35.7\%) were in the high-dose group. An increased ATO dosage was demonstrated to be an independent protective factor in terms of probability of relapse $(\mathrm{P}=0.004)$. With a median follow-up time of 53 months, the 4-year CIR was $16.7 \%$ in the low-dose group and $0 \%$ in the high-dose group, respectively $(\mathrm{P}=0.008)$. No patient relapsed when administered an ATO dosage $>6 \mathrm{mg} / \mathrm{kg}$. In conclusion, the relapse rate of APL was significantly associated with ATO dosage in post-remission therapy. An increased ATO dosage may serve as a protective factor of relapse. ATO dosage should therefore reach up to $12 \mathrm{mg} / \mathrm{kg}$, with consideration to reduce the dosage in the future.
\end{abstract}

Correspondence to: Dr Huaiyu Wang, Department of Hematology, First Affiliated Hospital of Xi'an Jiaotong University, 277 Yanta Western Road, Yanta, Xi'an, Shaanxi 710061, P.R. China E-mail: hywang@mail.xjtu.edu.cn

Key words: acute promyelocytic leukemia, relapse rate, arsenic trioxide, dosage

\section{Introduction}

Acute promyelocytic leukemia (APL) was once considered to be highly fatal because of its potential bleeding tendency. Relapse occurred in about $10-30 \%$ of patients with the treatment of all-trans retinoic acid (ATRA) and chemotherapy (CHT) (1-5). With the inclusion of arsenic trioxide (ATO), the relapse rate has decreased to $<10 \%$, and the cure rate has exceeded 90\% (4-7). Lo-Coco reported that, compared with ATRA-CHT, the ATRA-ATO combination significantly improved survival and relapse risk in patients with newly diagnosed, low- or intermediate-risk APL $(5,8)$. In AML17 trial, the researchers found similar results in high-risk APL patients (4).

In the ATRA and CHT era, the relapse rate was related to white blood cell (WBC) count at diagnosis, differentiation syndrome (DS), the expression of CD56 and body mass index (BMI) (9-12). In the ATRA and ATO era, it is unknown whether the above factors still affect the relapse rate. In addition, the relationship between the dosage of ATO and relapse rate needs to be elucidated.

Many studies have reported the cumulative side effects, long-term toxicity, and secondary carcinogenesis of ATO. In a 5-year follow up study, $\mathrm{Hu}$ et al performed systemic physical examination and laboratory studies to screen for possible toxic effects in 33 eligible patients treated with ATRA/ATO. The tests performed were as follows: Blood counts with peripheral smears, electrolyte panels with blood urea nitrogen and creatinine, urinalysis, liver function test, evaluation of serum tumor markers (CEA, AFP, CA199, CA125), electrocardiograms (ECGs) and echocardiograms, chest X-ray, dermatologic consultations, neurologic consultations, and nerve conduction velocity to test peripheral neurologic symptoms as necessary. All of these patients were in generally good condition and presented no skin lesions (13). In another study with 235 APL patients, Zhu et al reported that no arsenic accumulation or delayed toxicity was observed with over 10 years of follow-up (14). However, it was also reported that an increased risk of solid cancers and myelodysplasia were related to ATO $(15,16)$.

The actual dosage of ATO was extremely inconsistent in clinical pratice. In Shanghai Institute of Hematology, ATO was used at $0.16 \mathrm{mg} / \mathrm{kg} / \mathrm{d}$ for 30 days for 6 cycles, reached an accumulative dosage of $28.8 \mathrm{mg} / \mathrm{kg}$ in post-remission 
therapy (17). In M.D. Anderson Cancer Center, once in complete remission (CR), ATO was used at $0.15 \mathrm{mg} / \mathrm{kg}$ daily on Monday through Friday of weeks 1 to 4,9 to 12,17 to 20 , and 25 to 28 , reached an accumulative dosage of $12 \mathrm{mg} / \mathrm{kg}$ (18). In C9710 study, ATO was used at $0.15 \mathrm{mg} / \mathrm{kg} / \mathrm{d}$ for 5 days each week for 5 weeks for 2 courses after CR, reached an accumulative dosage of $7.5 \mathrm{mg} / \mathrm{kg}$ (19). According to the 2019 National Comprehensive Cancer Network (NCCN) guideline, the accumulative dosage of ATO in post-remission treatment ranges from $7.95-12 \mathrm{mg} / \mathrm{kg}$. Therefore, the optimal dosage of ATO needs to be further study. In this retrospective study, the relapse factors of APL and the appropriate dosage of ATO were to explored.

\section{Patients and methods}

Patients. This study retrospectively analyzed 112 patients diagnosed with APL between July 2008 and December 2015, from First Affiliated Hospital of Xi'an Jiaotong University and The First People's Hospital of Yulin. Eligibility criteria included: Morphologic diagnosis of de novo APL according to French-American-British criteria; demonstration of PML-RAR $\alpha$ fusion transcripts by reverse-transcriptase-polymerase-chain-reaction (RT-PCR) or the $\mathrm{t}(15 ; 17)$ translocation by means of conventional karyotyping or fluorescence in situ hybridization (FISH); Obtaining CR after induction therapy; age older than 1 year with no upper limit; normal left ventricular ejection fraction and Q-Tc interval less than $500 \mathrm{~ms}$; a negative pregnancy test in females of child-bearing potential; absence of serious comorbidity.

In this retrospective study, the difference of the accumulative ATO dosage in post-remission therapy was due to age and side effects from treatment. The recommended accumulative ATO dosage in post-remission therapy on 2019 NCCN guideline was $7.95-12 \mathrm{mg} / \mathrm{kg} .12 \mathrm{mg} / \mathrm{kg}$ ATO was the most widely used in clinical practice. Based on the actual dosage of ATO in post-remission therapy, a total of 112 APL patients were divided into the high-dose group (ATO dosage $\geq 12 \mathrm{mg} / \mathrm{kg}$ ) and low-dose group $(<12 \mathrm{mg} / \mathrm{kg})$. This study was approved by the Ethical Committee of the First Affiliated Hospital of Xi'an Jiaotong University in Xi'an, China (approval document no. 2015-012).

Treatment. In this retrospective study, 112 patients with newly diagnosed APL received the combination of ATRA, anthracycline-based chemotherapy and different dose of ATO for variable cycles. The induction comprised $25 \mathrm{mg} / \mathrm{m}^{2} / \mathrm{d}$ ATRA in two divided doses until CR, $0.15 \mathrm{mg} / \mathrm{kg} / \mathrm{d}$ intravenous ATO until CR, anthracyclines on days 1-3, and cytarabine on days 1-7. The post-remission treatment included $25 \mathrm{mg} / \mathrm{m}^{2} / \mathrm{d}$ ATRA for 2 weeks every 4 weeks for a total of 7-12 courses, anthracycline-based chemotherapy for more than 2 courses. ATO was used at $0.15 \mathrm{mg} / \mathrm{kg} / \mathrm{d}$ for different courses.

In the whole courses of treatment, the dose of ATRA, ATO, and chemotherapy were adjusted according to age and side effects.

Supportive measures, and management of complications. To prevent and treat the APL associated coagulopathy, platelet concentrates were used to maintain the platelet count
$>20 \times 10^{9} / 1$, and fresh-frozen plasma was transfused to maintain fibrinogen $>1.5 \mathrm{~g} / 1$. To improve the anemia, packed red cells were transfused to maintain hemoglobin levels $>60 \mathrm{~g} / \mathrm{l}$ (20). All patients received hydroxyurea based on WBC counts to control hyperleukocytosis. When DS was suspected clinically, ATRA, ATO, or both were temporarily discontinued, and $10 \mathrm{mg} / 12 \mathrm{~h}$ dexamethasones were given for a minimum of 3 days until the disappearance of symptoms and signs. Prophylactic heparin and Granulocyte Colony Stimulating Factor (G-CSF) were not recommended.

Definitions and endpoints. CR and relapse were defined using conventional criteria (21). Hematologic CR required that patients achieved the morphologic leukemia-free state of bone marrow (BM) and had the absolute neutrophils $>1.0 \times 10^{9} / 1$, platelets $>100 \times 10^{9} / 1$ in the peripheral blood. Molecular CR assessed by RT-PCR was defined as undetectable PML-RAR $\alpha$ transcript. Hematologic relapse was diagnosed based on the presence of $>20 \%$ blasts or abnormal promyelocytes in the BM. Molecular relapse was defined as the reappearance of the PML-RAR $\alpha$-specific band in two consecutive BM samples collected at any time after molecular CR (22).

RT-PCR analysis. Bone-marrow quantitative RT-PCR for PML-RAR $\alpha$ was performed in all patients at diagnosis, after induction, each consolidation cycle, and then every 3 months for 2 years.

Statistical analysis. Statistical analysis was performed by SPSS Version 18.0 statistical software. Comparisons were made using Student's t-test or the Mann-Whitney test for comparison of continuous variables and Pearson's $\chi^{2}$ test for dichotomous variables. Chi-square test or Fisher's exact test will be used for comparison of categorical variables between the two groups. The survival functions were estimated by using the Kaplan-Meier method and were compared by using the log-rank test. Multiple factor analysis and OR were determined by the the binary logistic regression analysis. All tests were two-sided, accepting $\mathrm{P}<0.05$ as indicating a statistically significant difference.

\section{Results}

Patient characteristics at presentation. A total of 112 patients were enrolled from July 2008 to December 2015. These included five children, age range from 4 to 13 years, three in the high-dose group, and two in the low-dose group. All patients' main clinical data at presentation were shown in Table I. Based on the accumulative actual ATO dosage in post-remission therapy, $72(64.3 \%)$ patients were in the low-dose group, whereas $40(35.7 \%)$ patients were in the high-dose group. The median ATO dosage was 4.83 and $15.59 \mathrm{mg} / \mathrm{kg}$ in the low-dose group and high-dose group respectively. DS occurred in 14 $(19.44 \%)$ patients in the low-dose group and 8 (20.0\%) patients in the high-dose group $(\mathrm{P}=0.94)$. There was no significant difference in the baseline characteristics between the two groups, including age, sex, WBC counts, PLT counts, Sanz risk and $P M L-R A R \alpha$ transcript type. All of 112 enrolled patients obtained CR, and the median time to achieve CR is 33 days 
Table I. Patient characteristics at diagnosis.

\begin{tabular}{lcc}
\hline Characteristics & Low-dose group $(\mathrm{n}=72)$ & High-dose group $(\mathrm{n}=40)$ \\
\hline Median age, years (range) & $38(8-65)$ & $36.5(4-76)$ \\
Sex, no. $(\%)$ & $36(50.0)$ & $25(62.5)$ \\
Male & $36(50.0)$ & $15(37.5)$ \\
Female & $1.24(0.5-157.3)$ & $1.42(0.71-91.19)$ \\
Median WBC, $\times 10^{9} / 1$ (range) & $45.5(2-118)$ & $34(8-115)$ \\
Median PLT, $\times 10^{9} /$ (range) & & $32(80.0)$ \\
Sanz risk, no. $(\%)$ & $61(84.7)$ & $8(30.0)$ \\
Low- or intermediate & $11(15.3)$ & 0.20 \\
High & & $27(67.5)$ \\
PML/RARA, no. $(\%)$ & $43(59.7)$ & $13(32.5)$ \\
BCR1-2 & $29(40.3)$ & 0.29 \\
BCR3 & & $8(20.0)$ \\
DS, no. $(\%)$ & $14(19.4)$ & $32(80.0)$ \\
Yes & $58(25.0)$ & 0.42 \\
No & & 0.94 \\
\hline
\end{tabular}

Low-dose group, ATO dosage in post-remission therapy $<12 \mathrm{mg} / \mathrm{kg}$; high-dose group, ATO dosage in post-remission therapy $\geq 12 \mathrm{mg} / \mathrm{kg}$. WBC, white blood cell; PLT, platelet; DS, differentiation syndrome; ATO, arsenic trioxide; PML/RARA, promyelocytic leukemia/retinoic acid receptor alpha; BCR, breakpoint cluster regions.

Table II. CIR by patient characteristics.

\begin{tabular}{lcc}
\hline Characteristic & CIR $(\%)$ & P-value \\
\hline All patients & 10.7 & \\
ATO dosage in post-remission therapy & & $<0.01$ \\
Low-dose group & 16.7 & \\
High-dose group & 0.0 & \\
WBC at diagnosis & & 0.23 \\
$\leq 10 \times 10^{9} / 1$ & 8.6 & \\
$>10 \times 10^{9} / 1$ & 21.1 & \\
PML/RARA & & 0.99 \\
BCR1-2 & 11.4 & \\
BCR3 & 5.7 & \\
Differentiation syndrome & & 0.91 \\
Yes & 13.6 & \\
No & 10.0 & \\
\hline
\end{tabular}

CIR, Cumulative incidence of relapse; ATO, arsenic trioxide; WBC, white blood cell; PML/RARA, promyelocytic leukemia/retinoic acid receptor alpha; BCR, breakpoint cluster regions.

(range, 25-46 days). There was no death during the follow-up period.

Cumulative incidence of relapse. The median follow-up of 112 patients considered for the CIR estimate was 53 months (range, 3 to 125 months). $12(10.71 \%)$ out of 112 patients relapsed during the follow-up. Table II shows the 4-year
Table III. Multivariate analysis of the risk factors of relapse in acute promyelocytic leukemia.

\begin{tabular}{lrc}
\hline Variable & P-value & Odds ratio $(95 \% \mathrm{CI})$ \\
\hline Age & 0.53 & $0.98(0.93,1.04)$ \\
WBC count & 0.85 & $1.00(0.98,1.03)$ \\
The occurrence of DS & 0.84 & $0.85(0.17,4.34)$ \\
ATO dosage & $<0.01$ & $0.67(0.51,0.88)$
\end{tabular}

WBC, white blood cell; ATO, arsenic trioxide; CI, confidence interval; DS, differentiation syndrome.

CIR values according to ATO dosage in post-remission treatment, WBC counts, PML/RARA transcript, and DS in single factor analysis. No statistically significant associations were detected between WBC counts, $P M L-R A R \alpha$ transcript type, the occurrence of DS and CIR. The accumulative ATO dosage in post-remission treatment was the only one relative factor of relapse.

The Binary logistic regression analysis was performed to define the risk factors of relapse for a total of 112 patients in Table III. An increased ATO dosage has an independent protective factor in terms of probability of relapse (odds ratio $=0.67,95 \% \mathrm{CI}, 0.51-0.88, \mathrm{P}=0.004)$. Age, WBC count, and the occurrence of DS had no relationship with the relapse rate $(\mathrm{P}>0.05)$. This result was consistent with the single factor analysis.

As shown in Fig. 1, the 4-year cumulative incidence of relapse (CIR) was $16.7 \%$ in the low-dose group and $0 \%$ in the high-dose group respectively $(\mathrm{P}=0.008)$. The median relapse 


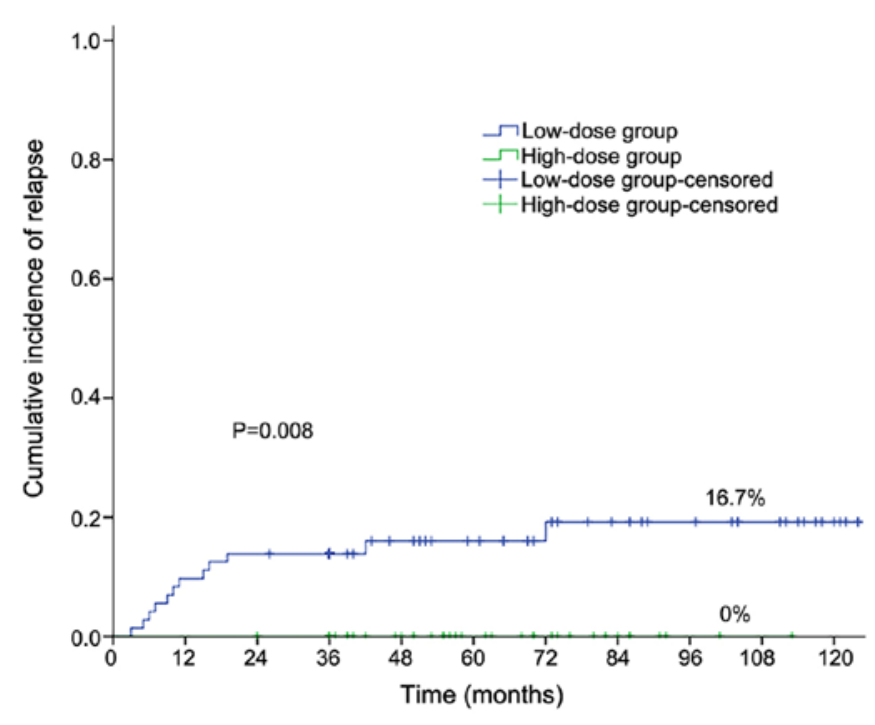

Figure 1. Time to relapse for the low-dose and high-dose groups.

time was 13 months (range, 3-42 months). Low-dose ATO was associated with higher CIR.

Among the 112 patients, we observed no one relapsed when the ATO dosage in post-remission more than $6 \mathrm{mg} / \mathrm{kg}$. The 4-year CIR was $23.5 \%$ in the patients received ATO less than $6 \mathrm{mg} / \mathrm{kg}$.

Toxicity. In previous studies, ATO rarely caused hematologic toxicixities, including neutropenia and thrombocytopenia. Therefore, we only discussed nonhematologic toxicities in this study. As is shown in Table IV, the incidence of hepatic toxicity was significantly higher in high-dose group than that of the low-dose group. No one has cardiac function (grade 3-4) in two groups. Only one patient developed chronic renal insufficiency in the high-dose group. There was no significant difference between the two groups in nephrotoxicity and skin reaction. One patient was diagnosed with breast cancer after finishing the treatment of ATO for 3 years.

\section{Discussion}

In APML3 trial, ATRA/idarubicin-based protocol produced durable remissions in most patients, but the relapse rate was up to $28.1 \%$ (3). Comparing with APML3, APML4 patients were treated with ATO in both induction and consolidation (6), and the relapse rate decreased to 5\%. APL0406 and AML17 trial showed similar results of the reduced relapse rate with ATO-based combination therapy (4,5). The addition of ATO was greatly related to the relapse of APL. In this retrospective study, the accumulative ATO dosage in post-remission treatment was the only relative factor of relapse based on the single and multiple factor analysis. The relapse rate was significantly lower in the high-dose group $(0 \%)$ than it in the low-dose group (16.7\%, P=0.004). High-dose ATO really reduced the relapse rate statistically. The relapse rate was not related to age, WBC counts and DS.

In previous studies, the ATO was effective at the total dosage from 7.5 to $28 \mathrm{mg} / \mathrm{kg}$ in post-remission therapy (17-19). Currently, the dose of ATO was significantly different in
Table IV. Toxicity.

\begin{tabular}{lccc}
\hline & $\begin{array}{c}\text { Low-dose } \\
\text { group } \\
\text { Toxicity }\end{array}$ & $\begin{array}{c}\text { High-dose } \\
\text { group } \\
(\mathrm{n}=72)\end{array}$ & $\begin{array}{c}(\mathrm{n}=40) \\
\text { P-value }\end{array}$ \\
\hline Hepatic toxicity (grade 3-4) & 7 & 11 & 0.01 \\
Cardiac function (grade 3-4) & 0 & 0 & \\
Nephrotoxicity (grade 3-4) & 0 & 1 & 0.36 \\
Skin reaction & 2 & 3 & 0.35 \\
Secondary tumor & 0 & 1 & 0.36 \\
\hline
\end{tabular}

different trials. In APL0406 trial, the prescribed dose was $0.15 \mathrm{mg} / \mathrm{kg} / \mathrm{d}$, and the total dosage in post-remission was $12 \mathrm{mg} / \mathrm{kg}$ (5). The same daily dose was used in APML4 trial, but the total dosage was $7.95 \mathrm{mg} / \mathrm{kg}$ (6). Besides, 0.25 or $0.3 \mathrm{mg} / \mathrm{kg} / \mathrm{d}$ ATO was given to participants in AML17 trial, and the total dosage was at the same as APL0406 trial (4). All of three trials resulted in $\leq 5 \%$ of 4 -year CIR. These showed that the ATO was active at a wide range of dosage. Although ATO is highly effective in the treatment of APL, it is a toxic agent known for centuries. The toxicity should be taken into account, including QT interval prolongation, severe ventricular arrhythmia, hyperlipidemia, liver and kidney dysfunction, skin reaction. An increased risk of solid cancers was recognized after long-term exposure to arsenic compounds (16), and myelodysplasia was also reported (15). It has been demonstrated that the occurrence of some toxic events could be reduced in the lower-dose group than those in the higher-dose group (23). We also found the ATO-related side effects were relatively low in the low-dose group. It is necessary to explore the optimal ATO dosage to minimize the side effects while obtaining high antileukemic efficacy.

In our study, when the ATO dosage in post-remission treatment was more than $6 \mathrm{mg} / \mathrm{kg}$, no one among the 112 patients relapsed. That was, the CIR is $0 \%$ regardless of the ATO dosage greater than $12 \mathrm{mg} / \mathrm{kg}$ or $6 \mathrm{mg} / \mathrm{kg}$. While the CIR was $23.5 \%$ with patients received ATO less than $6 \mathrm{mg} / \mathrm{kg}$. Therefore, the total dosage of ATO could be reduced appropriately. This could decrease drug-related adverse events and achieve therapeutic effects as well.

In this study, the patients with ATO dosage $\geq 6 \mathrm{mg} / \mathrm{kg}$ had significantly lower relapse rate than those in previous APL trials. The reason for the lower relapse rate may be the different schedule of ATRA and ATO. In other studies, the cycles and courses of ATRA and ATO were different, which resulted in that patients did not start and stop taking above two medicines at the same time. For example, patients received ATRA for 2 weeks every 4 weeks, and ATO for 4 weeks every 8 weeks in APL0406 trial. In this study, most patients received ATRA and ATO simultaneously for 2 weeks every 4 weeks. It has been reported that receiving ATRA and ATO simultaneously could accelerate the degradation of PML-RAR $\alpha$ fusing protein (13). We started a trial about the simultaneous application of ATRA and ATO in post-remission therapy. It was registered with the Chinese Clinical Trial Registry (ChiCTR-IPR-15006821) (24). To date, none of the participants relapsed. Therefore, the lower 
relapse rate may be related to the simultaneous application of ATRA and ATO.

In conclusion, our real-world results support that increasing dosage of ATO could reduce the relapse risk of APL, and the ATO dosage could be decreased appropriately in the future. The number of patients evaluated in this study is not enough, the prospective, randomized, controlled trials are needed to explore the optimal ATO dosage in the future.

\section{Acknowledgements}

The authors would like to thank Dr Xiaorui Wang (Xian No. 1 Hospital) for assisting with language editing. The abstract was presented at the $24 \mathrm{rth}$ congress of the European Hematology Association June 13-16 2019 in Amsterdam and published as abstract no. PF258 in HemaSphere 3 (Suppl 1) p81, 2019.

\section{Funding}

This work was supported by the Clinical Research Award Fund of First Affiliated Hospital of Xi'an Jiaotong University (grant no. XJTU1AF2016LSL-017) and the Shaanxi National Science Foundation (grant no. 2016JM8113).

\section{Availability of data and materials}

The datasets used and/or analyzed during the current study are available from the corresponding author on reasonable request.

\section{Authors' contributions}

SG analyzed and interpreted the data, performed statistical analysis and wrote the manuscript. HZ helped with the data analysis. WL, XZ and CZ acquired the data. HW conceived and designed the research. All authors read and approved the final manuscript.

\section{Ethics approval and consent to participate}

The current study was approved by the Ethical Committee of the First Affiliated Hospital of Xi'an Jiaotong University in Xi'an, China (Approval no. 2015-012) and was conducted in accordance with the Declaration of Helsinki.

\section{Patient consent for publication}

Not applicable.

\section{Competing interests}

The authors declare that they have no competing interests.

\section{References}

1. Sanz MA, Montesinos P, Vellenga E, Rayón C, de la Serna J, Parody R, Bergua JM, León A, Negri S, González M, et al: Risk-adapted treatment of acute promyelocytic leukemia with all-trans retinoic acid and anthracycline monochemotherapy: Long-term outcome of the LPA 99 multicenter study by the PETHEMA group. Blood 112: 3130-3134, 2008.
2. Lo-Coco F, Avvisati G, Vignetti M, Breccia M, Gallo E, Rambaldi A, Paoloni F, Fioritoni G, Ferrara F, Specchia G, et al: Front-line treatment of acute promyelocytic leukemia with AIDA induction followed by risk-adapted consolidation for adults younger than 61 years: Results of the AIDA-2000 trial of the GIMEMA group. Blood 116: 3171-3179, 2010.

3. Iland H, Bradstock K, Seymour J, Hertzberg M, Grigg A, Taylor K, Catalano J, Cannell P, Horvath N, Deveridge S, et al: Results of the APML3 trial incorporating all-trans-retinoic acid and idarubicin in both induction and consolidation as initial therapy for patients with acute promyelocytic leukemia. Haematologica 97: 227-234, 2012.

4. Burnett AK, Russell NH, Hills RK, Bowen D, Kell J, Knapper S, Morgan YG, Lok J, Grech A, Jones G, et al: Arsenic trioxide and all-trans retinoic acid treatment for acute promyelocytic leukaemia in all risk groups (AML17): Results of a randomised, controlled, phase 3 trial. Lancet Oncol 16: 1295-1305, 2015.

5. Platzbecker U, Avvisati G, Cicconi L, Thiede C, Paoloni F, Vignetti M, Ferrara F, Divona M, Albano F, Efficace F, et al: Improved outcomes with retinoic acid and arsenic trioxide compared with retinoic acid and chemotherapy in non-high-risk acute promyelocytic leukemia: Final results of the Randomized Italian-German APL0406 trial. J Clin Oncol 35: 605-612, 2017.

6. Iland HJ, Collins M, Bradstock K, Supple SG, Catalano A, Hertzberg M, Browett P, Grigg A, Firkin F, Campbell LJ, et al: Use of arsenic trioxide in remission induction and consolidation therapy for acute promyelocytic leukaemia in the Australasian Leukaemia and Lymphoma group (ALLG) APML4 study: A non-randomised phase 2 trial. Lancet Haematol 2: e357-e366, 2015.

7. Abaza Y, Kantarjian H, Garcia-Manero G, Estey E, Borthakur G, Jabbour E, Faderl S, O'Brien S, Wierda W, Pierce S, et al: Long-term outcome of acute promyelocytic leukemia treated with all-trans-retinoic acid, arsenic trioxide, and gemtuzumab. Blood 129: 1275-1283, 2017.

8. Lo-Coco F, Avvisati G, Vignetti M, Thiede C, Orlando SM, Iacobelli S, Ferrara F, Fazi P, Cicconi L, Di Bona E, et al: Retinoic acid and arsenic trioxide for acute promyelocytic leukemia. N Engl J Med 369: 111-121, 2013.

9. Sanz MA, Lo Coco F, Martin G, Avvisati G, Rayón C, Barbui T, Díaz-Mediavilla J, Fioritoni G, González JD, Liso V, et al: Definition of relapse risk and role of nonanthracycline drugs for consolidation in patients with acute promyelocytic leukemia: A joint study of the PETHEMA and GIMEMA cooperative groups. Blood 96: 1247-1253, 2000.

10. De Botton S, Chevret S, Coiteux V, Dombret H, Sanz M, San Miguel J, Caillot D, Vekhoff A, Gardembas M, Stamatoulas A, et al: Early onset of chemotherapy can reduce the incidence of ATRA syndrome in newly diagnosed acute promyelocytic leukemia (APL) with low white blood cell counts: Results from APL 93 trial. Leukemia 17: 339-342, 2003.

11. Montesinos P, Rayón C, Vellenga E, Brunet S, González J, González M, Holowiecka A, Esteve J, Bergua J, González JD, et al: Clinical significance of CD56 expression in patients with acute promyelocytic leukemia treated with all-trans retinoic acid and anthracycline-based regimens. Blood 117: 1799-1805, 2011.

12. Breccia M, Mazzarella L, Bagnardi V, Disalvatore D, Loglisci G, Cimino G, Testi AM, Avvisati G, Petti MC, Minotti C, et al: Increased BMI correlates with higher risk of disease relapse and differentiation syndrome in patients with acute promyelocytic leukemia treated with the AIDA protocols. Blood 119: 49-54, 2012.

13. Hu J, Liu YF, Wu CF, Xu F, Shen ZX, Zhu YM, Li JM, Tang W, Zhao WL, Wu W, et al: Long-term efficacy and safety of all-trans retinoic acid/arsenic trioxide-based therapy in newly diagnosed acute promyelocytic leukemia. Proc Natl Acad Sci USA 106: 3342-3347, 2009

14. Zhu HH, Wu DP, Jin J, Li JY, Ma J, Wang JX, Chen SJ and Huang XJ: Long-term survival of acute promyelocytic leukaemia patients treated with arsenic and retinoic acid. Br J Haematol 174: 820-822, 2016.

15. Rezuke WN, Anderson C, Pastuszak WT, Conway SR and Firshein SI: Arsenic intoxication presenting as a myelodysplastic syndrome: A case report. Am J Hematol 36: 291-293, 1991.

16. Firkin F: Carcinogenic risk of retained arsenic after successful treatment of acute promyelocytic leukemia with arsenic trioxide: A cause for concern? Leuk Lymphoma 55: 977-978, 2014. 
17. Shen ZX, Shi ZZ, Fang J, Gu BW, Li JM, Zhu YM, Shi JY, Zheng PZ, Yan H, Liu YF, et al: All-trans retinoic acid/As2O3 combination yields a high quality remission and survival in newly diagnosed acute promyelocytic leukemia. Proc Natl Acad Sci USA 101: 5328-5335, 2004.

18. Estey E, Garcia-Manero G, Ferrajoli A, Faderl S, Verstovsek S, Jones D and Kantarjian H: Use of all-trans retinoic acid plus arsenic trioxide as an alternative to chemotherapy in untreated acute promyelocytic leukemia. Blood 107: 3469-3473, 2006.

19. Powell BL, Moser B, Stock W, Gallagher RE, Willman CL, Stone RM, Rowe JM, Coutre S, Feusner JH, Gregory J, et al: Arsenic trioxide improves event-free and overall survival for adults with acute promyelocytic leukemia: North American leukemia intergroup study C9710. Blood 116: 3751-3757, 2010.

20. Junbo Ge and Yongjian Xu: Internal Medicine. 8th Edition. People's Medical Publishing house, Beijing, pp928-932, 2014.

21. Ye Y, Gaugler B, Mohty $M$ and Malard F: Old dog, new trick: Trivalent arsenic as an immunomodulatory drug. $\mathrm{Br}$ J Pharmacol 177: 2199-2214, 2020.
22. Cheson BD, Bennett JM, Kopecky KJ, Büchner T, Willman CL, Estey EH, Schiffer CA, Doehner H, Tallman MS, Lister TA, et al: Revised recommendations of the international working group for diagnosis, standardization of response criteria, treatment outcomes, and reporting standards for therapeutic trials in acute myeloid leukemia. J Clin Oncol 21: 4642-4649, 2003.

23. Lo Coco F, Diverio D, Avvisati G, Petti MC, Meloni G, Pogliani EM, Biondi A, Rossi G, Carlo-Stella C, Selleri C, et al: Therapy of molecular relapse in acute promyelocytic leukemia. Blood 94: 2225-2229, 1999.

24. Zhang X, Zhang H, Chen L, Wang M, Xi J, Liu X, Xie M, Li D, Gulati ES, Gong S and Wang H: Arsenic trioxide and all-trans retinoic acid (ATRA) treatment for acute promyelocytic leukemia in all risk groups: Study protocol for a randomized controlled trial. Trials 19: 476, 2018 